\title{
Growth of foetal thymus - A study of it's morphogenesis in human
}

\author{
J K Sarkar ${ }^{*}$, T Sinha $^{2}$, B C Dutta ${ }^{3}$ \\ ${ }^{1,2}$ Associate Professor, ${ }^{3}$ Professor, Department of Anatomy, Silchar M edical College, P.O. Ghungoor, Silchar-14, Cachar, Assam, INDIA. \\ Email: jksarkar31@gmail.com,dr.turlikasinha@ rediffmail.com,drbijondutta@gmail.com
}

\begin{abstract}
Aims and Objectives: Aim of the study was to find out the appearance, location, size and weight of the thymus in different age group of human foetus. Our objective was to correlate growth of foetal thymus with gestational age, body weight and crown rump length. Materials and Methods: The study was carried out on 90 human foetuses (48 male and 42 female) ranging from 9-38 weeks of gestation following spontaneous loss, elective termination and stillborn without congenital anomalies. The collected fetuses were examined for their Crown rump length and body weight. Then thymus were taken out by dissection of the foetuses. The gland so obtained were examined and weight measured. Results and Observations: Mean weight of thymus and foetus were calculated with standard deviations. The weight of the thymus increased steadily from 9-20 weeks. Thereafter growth rate was more up to 38 weeks of gestation. Therefore, growth rate of thymus with respect to gestational age and body weight of foetuses was nonlinear and relative weight of thymus increased more steeply than the foetal weight. The statistical analysis was done by (ANOVA) GraphPad InStat Software that revealed Pearson's Correlation coefficient $(r)=0.94$, 95\% confidence interval: 0.85 to 0.98 and Coefficient of determination ( $\mathrm{r}$ squared $)=0.89$. As the $\mathrm{r}$ value is closer to +1 , the correlation between weights of thymus with respect to gestational age is significant. All the findings of this present study were then compared with findings of different researchers and their literature. Conclusion: The relationship of the growth of thymus to gestational age is nonlinear. There was no significant sex difference between male and female foetus in regards to their morphology of the thymus.

Key Words: Thymus, morphology, foetus and gestation.
\end{abstract}

*Address for Correspondence:

Dr. J. K. Sarkar, Associate Professor, Department of Anatomy, Silchar Medical College, P.O. Ghungoor, Silchar-14, Cachar, Assam, INDIA. Email: jksarkar31@ gmail.com

Received Date: 14/12/2017 Revised Date: 03/01/2018 Accepted Date: 20/01/2018

DOI: https://doi.org/10.26611/1001511

\begin{tabular}{|l|l|}
\hline \multicolumn{2}{|c|}{ Access this article online } \\
\hline Quick Response Code: & Website: \\
\hline & www.medpulse.in \\
\cline { 1 - 2 } & 23 January 2018 \\
\hline
\end{tabular}

\section{INTRODUCTION}

The thymus is a primary lymphoid and vital human organ, acts as a regulator of the immune system which produces immunocompetent $\mathrm{T}$-cell and responsible for cell mediated immunity of the body. The greater part of thymus is situated in superior and anterior inferior mediastinum and lower border of the thymus reaches the level of $4^{\text {th }}$ costal cartilage. The gland commonly extends in superior aspect into the neck reaching sometimes the inferior pole of the thyroid or even higher. It is a soft bilobed organ, deep red in fresh state due to its rich blood supply. With age it becomes thinner and grayer before yellowing as adipose tissue infiltrates the organ with decrease in the amount of lymphoid tissue. The thymus is largest relative to its body weight at birth, when its weight is $10-15 \mathrm{gm}^{1}$. The primitive right and left thymic rudiments are formed at $4^{\text {th }}$ week of gestation moving caudally to fuse at midline at the beginning of $8^{\text {th }}$ week of gestation. In the $10^{\text {th }}$ week of gestation, mesodermal derived fibrous connective tissue surrounding the vessels begin to invaginate the thymic rudiment effecting thymic epithelial proliferation and thymic lobulation ${ }^{2}$.

\section{MATERIALS AND METHODS}

The study was carried out on 90 human foetuses ranging from 9-38 weeks of gestation in the Department of Anatomy, Silchar Medical College and Hospital, Silchar, Assam. During the period of study 130 foetuses were obtained from the Department of Obstetrics and 
Gynaecology, Silchar Medical College and Hospital, Silchar following spontaneous loss, elective termination and stillborn without congenital anomalies. Out of these, 90 foetuses (48 male and 42 female) were selected for the present study.

Selection Criteria: Of the cases in this study were as follows: a) Absence of gross congenital anomalies, marked oedema and obvious maceration; b) No previous fixation; c) Absence of history of rubella infection. Race, maternal age, parity and cause or indications of abortion were immaterial in the selection. Mean maternal age and parity were 24.5 years and 2 respectively. The foetuses were collected and preserved in 10\% formalin. The time of obtaining the foetuses varied from one hour to ten hours after death. Most of the thymuses were examined within a few hours of delivery and always within 24 hours.
Dissections: Thymus was extirpated by disarticulating the sterno-clavicular joints and cutting out of costal cartilages. Thus the entire thoracic cavity was opened up. The lower part of the neck was also dissected for complete exposure of the thymus and its cervical extensions were recorded.

Measurements: The thymus and foetuses were weighed. Crown rump length was measured with millimeter roller. The estimation of gestational age was obtained by subtracting 14 days from the menstrual age. The particulars of the foetus and thymus were recorded. The findings were graphically presented and statistical analysis was done. All findings of this present study were then compared with findings of different researchers and their literature.

\section{RESULTS AND OBSERVATIONS}

Table 1: Mean weight of Thymus and Foetus with Standard Deviations, Mean of Thymus/Body Wt. ratio of ninety (90) Human foetuses from $9^{\text {th }}$ to $38^{\text {th }}$ weeks of gestation.

\begin{tabular}{|c|c|c|c|c|c|c|c|}
\hline \multirow{2}{*}{$\begin{array}{l}\text { Gestational } \\
\text { Age in weeks }\end{array}$} & \multirow{2}{*}{$\begin{array}{l}\text { No. of } \\
\text { Foetus }\end{array}$} & \multirow{2}{*}{$\begin{array}{l}\text { Mean } \\
\text { Crown rump } \\
\text { length }\end{array}$} & \multicolumn{2}{|c|}{$\begin{array}{c}\text { weight of Thymus in } \\
\text { grams }\end{array}$} & \multicolumn{2}{|c|}{$\begin{array}{c}\text { weight of foetus in } \\
\text { grams }\end{array}$} & \multirow{2}{*}{$\begin{array}{c}\text { Mean of } \\
\text { Thymus/ Body wt } \\
\text { ratio }\end{array}$} \\
\hline & & & Mean & SD & Mean & SD & \\
\hline 9 & 3 & 5.1 & 0.0133 & 0.0029 & 11.250 & 0.5568 & 0.00118 \\
\hline 10 & 6 & 6.1 & 0.0233 & 0.0041 & 13.717 & 0.4926 & 0.00166 \\
\hline 12 & 7 & 8.6 & 0.0729 & 0.0086 & 43.636 & 1.177 & 0.00167 \\
\hline 14 & 5 & 10.7 & 0.1970 & 0.0153 & 110.53 & 1.851 & 0.00178 \\
\hline 15 & 4 & 13.2 & 0.3050 & 0.0082 & 152.05 & 2.264 & 0.00201 \\
\hline 16 & 5 & 14.1 & 0.5250 & 0.0274 & 201.87 & 1.690 & 0.00260 \\
\hline 17 & 5 & 15.2 & 0.7060 & 0.0074 & 261.05 & 1.200 & 0.00270 \\
\hline 18 & 6 & 16.2 & 0.8900 & 0.0187 & 318.48 & 1.425 & 0.00279 \\
\hline 20 & 6 & 18.9 & 1.283 & 0.0309 & 454.32 & 2.314 & 0.00282 \\
\hline 22 & 6 & 21.1 & 1.810 & 0.0207 & 632.85 & 1.925 & 0.00286 \\
\hline 24 & 6 & 23.1 & 2.391 & 0.0652 & 822.13 & 2.240 & 0.00291 \\
\hline 26 & 4 & 25.1 & 3.115 & 0.1061 & 1002.9 & 6.736 & 0.00311 \\
\hline 28 & 4 & 27.1 & 4.620 & 0.0404 & 1286.6 & 13.966 & 0.00357 \\
\hline 30 & 4 & 28.1 & 6.579 & 0.0840 & 1705.8 & 4.933 & 0.00385 \\
\hline 32 & 4 & 30.1 & 8.191 & 0.0818 & 2107.4 & 5.768 & 0.00388 \\
\hline 34 & 5 & 31.2 & 9.960 & 0.0872 & 2518.3 & 1.660 & 0.00385 \\
\hline 36 & 5 & 33.6 & 11.197 & 0.0946 & 2906.9 & 8.354 & 0.00385 \\
\hline \multirow[t]{2}{*}{38} & 5 & 35.4 & 12.266 & 0.1622 & 3201.2 & 14.637 & 0.00383 \\
\hline & & $P \varangle 0.001$ & \multicolumn{2}{|c|}{ P value $<0.01$} & \multicolumn{2}{|c|}{ P value $\varangle 0.001$} & P value $\varangle 0.01$ \\
\hline
\end{tabular}

One-way Analysis of Variance (ANOVA) was done. ANOVA assumed that the data were sampled from populations that follow Gaussian distributions. This assumption is tested using the method Kolmogorov and Smirnov: Degrees of freedom: Treatments (between columns) 17 and Residuals (within columns) 72 


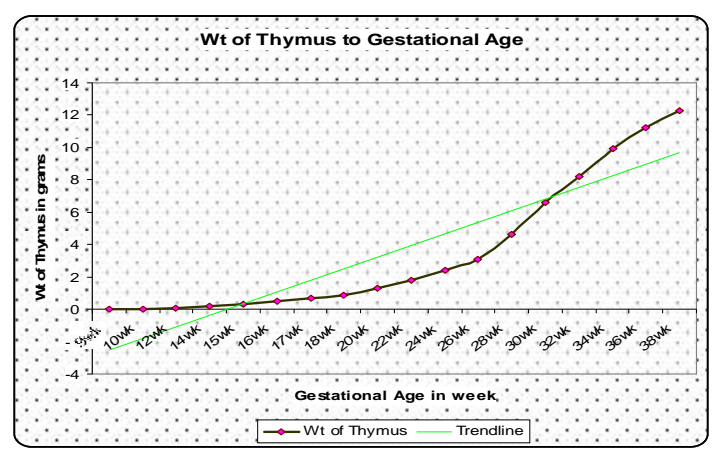

Figure 1

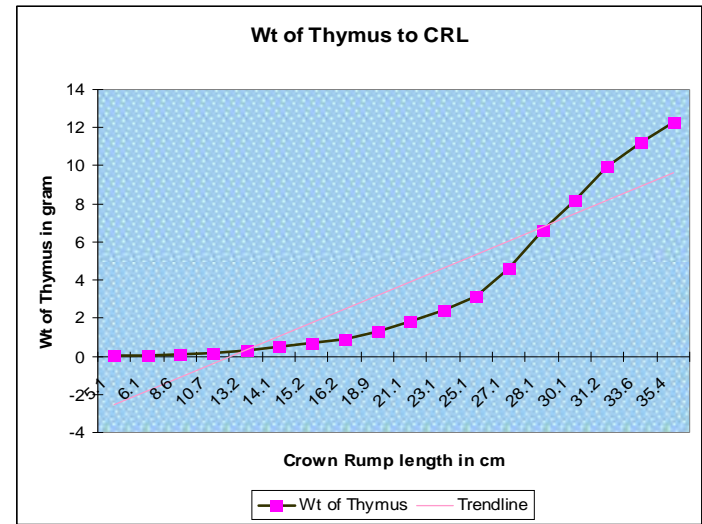

Figure 3

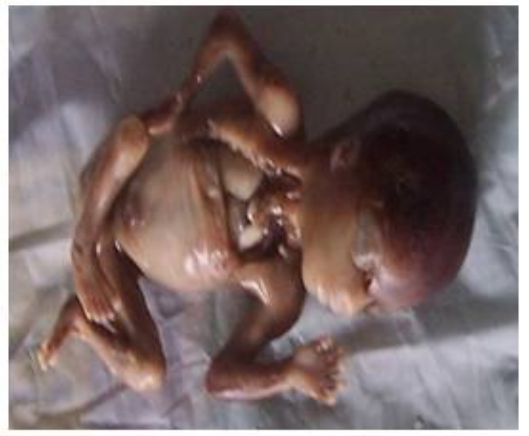

Figure 5

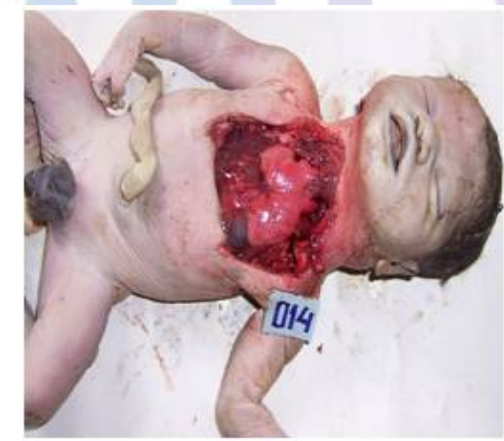

Figure 6

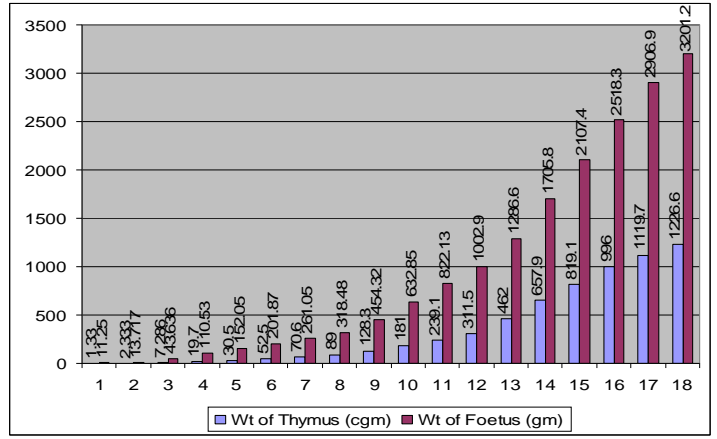

Figure 2

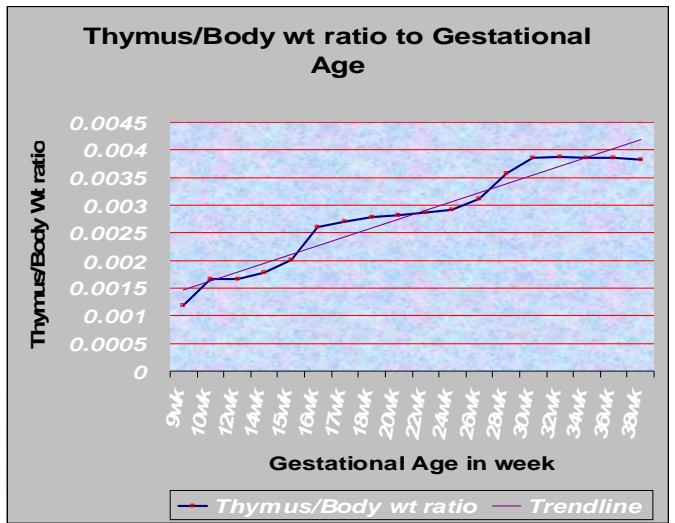

Figure 4

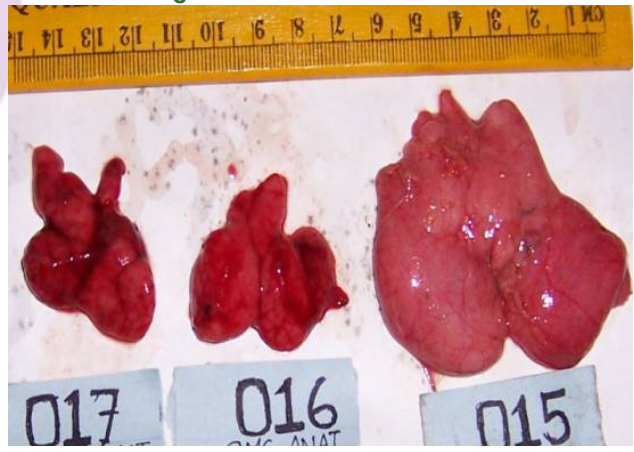

Figure 7

Legend

Figure 1: Line diagram showing the growth curve of thymus with respect to gestational age. Pearson's Correlation coefficient $(r)=0.96$ Figure 2: Bar chart showing the relationship of thymus to body weight of the foetus.

Figure 3: Graph showing the relationship of growth rate of thymus with respect to crown rump length of foetus.

Figure 4: Graph showing the relationship of ratios of weight of thymus to body weight with respect to gestational age. Pearsonian correlation of coefficient $(r)=0.95$

Figure 5: Photograph of foetal thymus at 17 weeks of gestation. Dissection to show the thymus and its extension into the neck. Figure 6: Dissection to show the thymus. Photograph of foetal thymus at 38 weeks of gestation.

Figure 7: Photograph of foetal thymus. Lobes are interconnected.

Appearance: The thymus is soft, bilobed organ and light pink in colour. Its two lobes lie close together side by side and joined in the midline by connective tissue (Fig. 5, 6, 7).

Location: The thymus is situated in superior and anterior inferior mediastinum. It extends from root of the neck to $4^{\text {th }}$ costal cartilages. Cervical extension into the lower border of the thyroid was observed in 4 cases (Fig-5).
Weight of the thymus and foetus: The mean weight of thymus and the foetus along with standard deviations were calculated. The mean of thymus to body weight ratios of the foetus were also calculated and were shown in Table-I. The mean values and standard deviations were calculated by using one-way analysis of variance (ANOVA) of GraphPad InStat Software. 
Weight of thymus with respect to gestational age: The weight of the thymus increased steadily from 9-20 weeks of gestation. Thereafter growth rate was more up to 38 weeks of gestation. Therefore, the growth rate of the thymus with respect to the gestational age was nonlinear which was represented graphically in Fig. 1. The statistical analysis revealed Pearson's Correlation coefficient $(r)=0.94,95 \%$ confidence interval: 0.85 to 0.98 and Coefficient of determination $(\mathrm{r}$ squared $)=0.89$. As the $r$ value is closer to +1 , the correlation between weights of thymus with respect to gestational age is significant.

Weight of thymus with respect to body weight of foetus: The growth rate of thymus with respect to body weight of the foetus was nonlinear. There was gradual increase in weight of thymus up to $1002.9 \mathrm{gm}$ of body weight of foetus. Thereafter, the relative weight of thymus increased more steeply than the foetal weight. The relationship of weight of thymus to its body weight was shown in Fig. 2. Karl Pearson's Correlation coefficient $(r)=0.99,95 \%$ confidence interval: 0.995 to 0.999 and coefficient of determination ( $\mathrm{r}$ squared) $=$ 0.996. Therefore, the relationship of growth of thymus with respect to body weight of the foetus is significant as the $r$ value is nearer to +1 .

Weight of thymus with respect to crown rump length: The Fig. 3 showed the growth curve of thymus with respect to the crown rump length. It was evident that there was increase in thymus weight with increase in body length.

Ratios of weight of thymus to body weight with respect to gestational age: The thymus had an increase in weight relative to body weight during 9-18weeks of gestation. The ratio of thymus to body weight increased between 20-30 weeks of gestation and then become constant. This relationship was shown in Fig.4. Pearsonian Correlation coefficient $(r)=0.95,95 \%$ confidence interval: 0.88 to 0.98 and coefficient of determination $(\mathrm{r}$ squared $)=0.91$

\section{DISCUSSION}

Results and observations obtained in the present study revealed several points of interest having marked importance in practical life. Hence these have been considered worthy of discussion in conjunction with the findings of other researchers to draw definitive conclusion in respect of morphological changes of thymus among different age groups human foetus.

Appearance: The foetal thymus was broad and variable in size and shape as unilobar, bilobar, trilobar or conglomerate $^{3}$. Thymus was described as soft, bilobed organ and the lobes were joined in the midline by connective tissue ${ }^{1,11}$. However in the present study, the thymus was soft, bilobed, broad and light pink in appearance. Its two lobes were interconnected (Fig. 5, 6, 7).

Location: It was reported that cervical thymus extended through superior thoracic aperture to reach the lower border of the thyroid cartilage ${ }^{4}$. Ghali et al cited cervical extension of thymic lobes that were connected to the base of thyroid gland ${ }^{5}$. Sahana reported that thymus extend from level of cricoid cartilage up to $4^{\text {th }}$ costal cartilage ${ }^{6}$. Horia Muresian reported extensions into the neck are common, and sometimes reaches the inferior poles of the thyroid gland or even higher ${ }^{1}$. In present study cervical extensions of thymus in 4 cases into the lower border of the thyroid were observed. (Fig. 5)

Growth of thymus with respect to gestational age: It was reported that thymus grew from the start quite regularly and attained greatest weight in $7^{\text {th }}$ foetal months. The relative weight of thymus increased continually ${ }^{7}$. The relation of thymus to gestational age was nonlinear and gradually increasing. Similarly in present study, the growth rate of thymus with respect to gestational age was nonlinear. The weight of the thymus increased steadily from 9-20 weeks of gestation. Thereafter growth rate was more up to 38 weeks of gestation. Fig. 1 showed the relationship of growth rate of thymus with respect to gestational age.

Growth of thymus with respect to body weight: The thymus had an increase in weight relative to body weight during the first one-half of foetal life and its weight steadily increased as body weight increased'. Shepard observed that the relation of thymus to body weight was nonlinear and gradually increasing ${ }^{8}$. In the present study, there was gradual increase in weight of thymus up to 1002.9 gm of body weight of foetus. Thereafter, the weight of thymus increased more steeply up to 3225.15grams of foetal weight and this relationship of thymus weight to it body weight was shown in Fig. 2.

Growth of the thymus with respect to crown rump length: Boyd reported that there was increase in thymus weight with increase in body length ${ }^{3}$. In the present study also, there was increase in weight of the thymus with the increase in crown rump length of the foetus. This correlation was represented graphically in Fig. 3 in where the correlation coefficient $(\mathrm{r})=+0.91$.

Ratio of thymus to body weight with respect to gestational age: The ratios for thymus to body weight in this study increased between 20 and 30 weeks gestation and then became constant(Fig. 4). Approximate mean organ weight/body weight ratio between 30 and 43 weeks gestation of thymus was 0.004 by Mitropoulos ${ }^{10}$. 


\section{CONCLUSION}

The thymus varies in size and development with the age of the foetus. The thymus is situated in superior and anterior inferior mediastinum, extending from root of the neck to 4th costal cartilages. Cervical extension of the gland into the inferior pole of the thyroid was noted in four fetuses of 18, 24, 27 and 38 weeks of gestation. The thymus consists of two lobes closely apposed to each other and are joined in the midline by connective tissues. The lobes are surrounded by connective tissue capsule. The relationship of the growth of thymus to gestational age as well as body weight of foetus is nonlinear. The growth of the thymus with respect to crown rump length of the foetus is also nonlinear. The ratio of thymus to body weight increased between 20 and 30 weeks of gestation. There was no significant sex difference between male and female foetuses in regards to their morphology of the thymus.

\section{REFERENCES}

1. Muresian H: Mediastinum: in Susan Standring, Gray's Anatomy, The Anatomical Basis of Clinical Practice, $41^{\text {st }}$ edition. 2016; 983-986

2. Lobach D F, Haynes B F: Ontogeny of the human thymus during foetal development: J Clin Immunol. 1987; 7: 8197
3. Boyd E: Growth of the thymus: its relation to status thymolymphaticus and thymic symptom: Am J Dis Child. 1927; 33: 867-879

4. Hollinshead W H: The thorax, Textbook of anatomy: 1967; 495-560

5. Ghali W M, Abdel-Rahman S, Nagib M, Mahran Z Y: Intrinsic innervation and vasculature of pre and postnatal human thymus: Acta Anat. 1980; 108: 115-123

6. Sahana S N: The thymus, Human anatomy, Vol-II, 4th edition. 1985 ; 454-457

7. Ekhlom E, Niemineva K: On prenatal changes in the relative weights of the adrenals, the thymus and the thyroid gland: Acta Paediat. 1950; 39: 67-86

8. Shepard et al: Organ weight standards for human fetuses: Pediatr Pathol. 1988; 8(5): 513-24

9. Tanimura T, Nelson T, Hollingsworth R R, Shepard T H: Weight standards for organs from early human fetuses: Anat. Rec. 1971; 171: 227-236

10. Mitropoulos G, Scurry J, Cussen L: Organ weight/bodyweight ratios: growth rates of foetal organs in the latter half of pregnancy with a simple method for calculating mean organ weights: J Paediatr Child Health. 1992 Jun; 28(3): 236-9

11. Ajita R K, Singh T N, Singh Y I, Singh L C: An insight into the structure of the thymus in human foetus- a histological approach: J. Anat. Soc. India. 2006 June; 55(1): 45-49.

\section{Source of Support: None Declared} Conflict of Interest: None Declared 